\title{
Iglesia, organizaciones populares y violencia sociopolítica
}

Capitalistas embrutecidos, perezosos y bribones muestran sus caras abotagadas y crueles a no menos crueles comunistas pedigüeños, sórdidos y rapaces. Mientras estos dos bandos en lodos sus grados de intensidad se gruñen unos a otros, nosotros los soñadores no pedimos nada porque todo lo tenemos.

Salarrie, Mi respuesta a los patriotas (1932).

\section{Introducción}

En la década de los años setenta se generó, en El Salvador, una situación de intensa conflictividad social y política, la cual estuvo directamente relacionada no sólo con el empeoramiento de las condiciones de vida de los sectores populares -obreros, campesinos, vendedoras de mercados, habitantes de tugurios-, sino con la exclusión política de la que hicieron gala los gobiemos del coronel Arturo Armando Molina y el general Carlos Humberto Romero, quienes llegaron al poder tras sendos fraudes electorales, en 1972 y 1977, respectivamente. En estos dos acontecimientos políticos tuvo un papel protagónico la Unión Nacional Opositora (UNO), integrada por el Partido Demócrata Cristiano (PDC), el Movimiento Nacional Revolucionario (MNR) y la Unión Democrática Nacionalista (UDN). La UNO, sin duda alguna el más importante frente político-electoral en la historia contemporánea de El Salvador, no era sólo expresión de las demandas de democratización y de resistencia al militarismo de la sociedad salvadoreña, sino que también representaba una salida relativamente pacífica. La Universidad Centroamericana "José Simeón Cañas" concluyó lo siguiente: "hay indicios poderosos de que en las elecciones presidenciales se cometió fraude. Estos indicios son incontrovertibles, aunque, en su carácter de indicios, son insuficientes para aportar pruebas contudentes y definitivas sobre resultados que modifiquen los dados oficialmente para la elección presidencial. Quien principal- 
mente proporcionó tales indicios fue el mismo CCE [Consejo Central de Elecciones] con su conducta. Es esta conducta del CCE la que justifica seguir todas las pistas que los datos revelen"'.

En las elecciones de 1977, la UNO participó con el coronel Emesto Claramout como candidato a la presidencia — su compañero de fórmula fue José Antonio Morales Erlich- y nuevamente fue víctima de un fraude electoral que llevó al poder al candidato del Partido de Conciliación Nacional, el general Carlos Humberto Romero. Ante este fraude, la protesta popular no se hizo esperar. Los dirigentes de la UNO y varios miles de sus seguidores -entre los que se encontraban vendedoras de los mercados, empleados, obreros, campesinos y estudiantes - se "tomaron" la Plaza Libertad en el centro de San Salvador. En la madrugada del 28 de febrero de ese año, unidades de los cuerpos de seguridad principalmente de la Policía Nacional y Guardia Nacional- desalojaron, con gases lacrimógenos y ráfagas de ametralladora, la concentración popular.

Fue en esta coyuntura que nacieron las "Ligas populares 28 de febrero", una organización popular que, junto al Bloque Popular Revolucionario (BPR), el Frente de Acción Popular Unificada (FAPU), el Movimiento de Liberación Popular (MLP) y la UDN, va a ocupar un lugar protagónico en el proceso sociopolítico de la década de los años setenta.

Las organizaciones populares -conocidos también como "Frentes de Masas"- tenían una composición social diversa, que iba desde sectores de la clase media (maestros y estudiantes) hasta sectores que estaban en la base de la pirámide social (pobladores de tugurios), pasando por vendedoras de los mercados, obreros y campesinos. Ciertamente, dentro de las organizaciones populares, fue particularmente importante el papel de los sectores campesinos, sobre todo porque la exclusión socioeconómica que pesaba sobre ellos - agudizada por el fracaso de la transformación agraria auspiciada por Molina en 1976 - los hacía más sensibles a iniciativas - como las de la Iglesia católica, a través de la Compañía de Jesús - encaminadas a fomentar la lucha por sus derechos, entre los cuales ocupaba un importante lugar el derecho a organizarse ${ }^{2}$.

En suma, la década de los años setenta fue de una gran densidad histórica: las necesidades de las mayorías populares y su ansia de hacer algo por cambiar las condiciones que les impedían llevar una vida digna, encontraron eco tanto en un sector de la Iglesia empeñado en historizar las enseñanzas de la fe cristiana como en un sector de las clases medias, influido fuertemente por las enseñanzas del marxismo-leninismo y el ejemplo de la revolución cubana. Sin la imbricación mutua - no exenta de tensiones y conflictos- de las opciones y valores que estos actores representaban, no se pueden comprender a cabalidad los dinamismos fundamentales de ese período histórico de El Salvador. Al igual que no se puede entender sin esa otra tríada de factores que se les añadieron: la violencia institucional, la violencia represivo-terrorista y la violencia revolocionaria. 
Recordar esa época - cronológicamente tan cercana, pero tan borrosa en la memoria colectiva - es el principal propósito de este artículo. Otro de sus propósito es hacerlo con la mirada puesta en el presente salvadoreño: ese presente que se inicia con los acuerdos de paz. Las preguntas que nos hacemos y que tratamos de responder son las siguientes: ¿qué fue lo que hizo posible, más allá de las presiones internacionales, terminar con el conflicto armado por la vía negociada? Más concretamente: ¿cuáles fueron los referentes de identidad político-religiosa que permitieron al FMLN avanzar desde una búsqueda por el control total del Estado a la aceptación de un esquema democrático? Por último: ¿qué ha quedado de esa época en la cultura política de los años noventa?

\section{Iglesia y organización popular campesina}

Desde 1932, la sindicalización campesina se convirtió en tema tabú para la oligarquía salvadoreña y para los sucesivos gobiemos militares que controlaron el aparato estatal. La organización de los campesinos no tenía cabida en las leyes, y cualquier voz que apuntara en la dirección de establecer ese derecho era acallada inmediatamente, ya fuese con la persuasión de un discurso anticomunista o con la violencia física. No es sino hasta 1976 que un gobiemo, el gobiemo del coronel Arturo Armando Molina, tiene la osadía no sólo de hablar oficialmente de organización campesina, sino de una "transformación agraria" . En efecto, en junio de 1976, la Asamblea Legislativa aprobó el "Decreto del Primer Proyecto de Transformación Agraria", a través del cual se establecían modificaciones importantes en el régimen de tenencia de la tierra en los Departamentos de Usulután y San Miguel, en la zona oriental del país ${ }^{4}$. Casi paralelamente a la aprobación del Proyecto de Transformación Agraria, la Asamblea Legislativa aprobó la "Ley de Creación del Instituto Salvadoreño de Transformación Agraria (ISTA)", el cual daba vigencia a una estructura legal e institucional mediante la cual se haría efectiva la transformación agraria ${ }^{5}$. Sin duda alguna, la creación del ISTA constituía un paso sin precedentes en el horizonte de la organización campesina en El Salvador, sobre todo considerando que se trataba de una iniciativa estatal ${ }^{h}$.

El Proyecto de Ley de transformación agraria, presentado por el gobiemo del coronel Molina, generó la inmediata movilización social en apoyo a la aprobación del mismo, movilización en la que participan activamente la Universidad Centroamericana "José Simeón Cañas", la Federación Cristiana de Campesinos Salvadoreños (FECCAS) y la Unión de Trabajadores del Campo (UTC) promoviendo seminarios y planteando nuevas propuestas. Por su parte, las presiones del gran capital y de los sectores terratenientes, aglutinados en el Frente de Agricultores de la Región Oriental (FARO), se hacen sentir sobre el gobiemo mediante una campaña que esos sectores realizan -a través de La Prensa Gráfica y El Diario de Hoy- con el fin de hacerlo desistir de sus propósitos reformistas. Al final, la batalla es ganada por los sectores opuestos a la transfor- 
mación agraria, ante quienes el gobiemo no tiene otra opción que decir "a sus órdenes, mi capital" (I. Ellacuría)'. Como resultado de la ofensiva oligárquica, en octubre de 1976 la Asamblea Legislativa aprueba el Decreto 123: "Reformas a las Leyes de Creación del Instituto Salvadoreño de Transformación Agraria y del Primer Proyecto de Transformación Agraria", mediante el cual se redefinen aquellos aspectos de las propuestas originales que más afectaban los intereses de los terratenientes ${ }^{\sharp}$.

Con Molina, pues, se aborta un intento de dotar a los trabajadores del campo -desde la esfera estatal- de un serie de derechos económicos, sociales y políticos fundamentales para hacer menos difíciles las condiciones de vida en el agro. Un resorte esencial para la conquista y consolidación de esos derechos era no sólo la transformación de las relaciones de propiedad en el campo, sino el fortalecimiento de la organización campesina. Aunque colapsado, el intento del gobiemo de Molina sentó las bases para que el tabú de la organización campesina dejara de serlo; la urgencia y necesidad de la misma no sólo se había vuelto tema de discusión en diferentes instancias gubernamentales y de la sociedad civil, sino que importantes sectores campesinos habían caído en la cuenta de la legitimidad y posibilidad de dotarse de estructuras organizativas que les permitiesen canalizar sus demandas. Una de las instancias que contribuyó a esa toma de conciencia campesina -incluso mucho antes del intento del gobiemo del coronel Molina - fue la Iglesia católica salvadoreña, que se tomó en serio el problema de la organización campesina y que lo asumió desde la década de los sesenta como un desafío pastoral fundamental.

\subsection{Los compromisos de la Iglesia con el poder}

La Iglesia católica ha tenido un enorme influjo en la realidad histórica salvadoreña, no sólo durante la colonia y el período conservador, sino en el período liberal, que se inicia a finales del siglo XIX cuando se produce la revolución liberal y se institucionaliza la Repúblicay. En este sentido, en el caso salvadoreno no es tan cierta la tesis - sostcnida por los liberales- de que la revolución liberal excluyó al poder eclesiástico de la esfera social, económica y política. Por el contrario, la Iglesia "tuvo la flexibilidad suficiente para reubicarse en el nuevo orden económico, social y político"'", y se mantuvo como una instancia de poder junto con las otras instancias de poder económico y político que se constituían en el momento de despegue de la república liberal.

El poder eclesiástico se caracterizó, desde finales del siglo XIX hasta los años cincuenta, por el apoyo casi monolítico de las autoridades eclesiásticas al proyecto socioeconómico y político impulsado por la clase gobernante, civil y militar, que se consolidó en el poder durante el primer cuarto del siglo XX. Rodolfo Cardenal - luego de un análisis exhaustivo de documentos oficiales de la Iglesia - resume así la percepción de la jerarquía eclesial, respecto a la lgle- 
sia, la sociedad, la religión y la política, durante este primer cuarto de siglo: "la Iglesia... tenía una misión dentro de la sociedad. La religión se consideraba obligada a civilizar, moralizar y unir al pueblo. Esta misión se llevaba a cabo mediante la formación de las conciencias. Es decir, la función social de la Iglesia estaba reducida al ámbito de la conciencia. En ella se daba el punto de coincidencia entre las dos esferas, lo político y lo religioso. En virtud de esta función social, el Estado estaba obligado a reconocer oficialmente a la religión y a protegerla. A su vez, la religión colaboraría enormemente en la conservación del orden establecido, evitando los cambios radicales. La religión se presentaba a sí misma como una garantía contra el odio del pueblo. Su fuerza estaba en la formación de las conciencias, la cual consistía en interiorizar en las conciencias de los ciudadanos el respeto y la veneración a las autoridades constituidas. Además, por medio de su labor uniría al pueblo con vínculos internos y permanentes garantizando el orden y la paz, condiciones indispensables para el progreso en que estaba empeñado el gobiemo"'!.

Si el compromiso con las autoridades constituidas por parte de la Iglesia era así de decidido, no era menos decidido su rechazo al socialismo y el comunismo. En 1927, el entonces Administrador Apostólico de la Arquidiósesis de San Salvador y futuro Arzobispo, Mons. Alfonso Belloso, emitió una Carta Patoral titulada "El presente momento social", documento en el cual se resume la postura de la Iglesia ante la doctrina socialista ${ }^{12}$. Pero el documento no tiene una finalidad meramente doctrinal, sino que su principal objetivo es político: a través del mismo la jerarquía eclesial desaprueba y condena el influjo del movimiento comunista en la coyuntura de la época. En un apartado de la Carta Pastoral de Mons. Belloso, titulado "El socialismo y la patria salvadoreña", se puede leer lo siguiente: "el socialismo, así como aborrece las ideas de la propiedad familiar, Estado, religión, así también abomina la idea de Patria. Las fronteras se le antojan coacción y tiranía, y ha jurado borrarlas; el hombre ha de ser ciudadano del universo; en el mundo socialista no habrá naciones, habrá sindicatos. Por consiguiente, en la geografía socialista no contará la República de El Salvador, sino la Confederación de Camaradas Salvadoreños"'!3.

Al referirse a los problemas nacionales, Mons. Belloso señala lo siguiente: "confiar la solución de problemas tan complejos y espinosos a mítines populares y a conferencias tendenciosas - por más que se adoren con los nombres de centros culturales y campañas contra el analfabetismo- sería reconocido desacierto. No necesitamos agrupaciones propagandísticas que lancen a los cuatro vientos ideas inspiradas por el comunismo extranjero, sino Círculos de Estudios que, de la observación directa de nuestra vida social íntima, infieran las causas y los remedios de sus dolencias. Invitamos, pues, a todos los intelectuales salvadoreños a esta labor tranquila y de veras provechosa... proponiéndoles para nuestra mutua inteligencia el siguiente criterio: El sistema económico-social más aceptable es 
el que mejor concilia el mayor bien posible del individuo con el mayor bien posible de la colectividad"14.

Esa conciliación suponía rechazar cualquier intento de reforma del modelo socioeconómico y político establecido. Y como este modelo se fundaba en el control sobre la tierra ejercido por un grupo de propietarios de las grandes haciendas cafetaleras, lo más temido era justamente la transformación de las relaciones de propiedad en el agro. El levantamiento campesino de 1932 se constituyó en una amenaza para la dominación de los grupos oligárquicos. Pero no sólo el ejército y los grupos paramilitares de la oligarquía lo enfrentaron, también lo hizo la Iglesia. Controlado el alzamiento campesino, su amenaza quedó presente como un fantasma para los grupos de poder. Reforma agraria y organización campesina fueron temas tabú para la élite dominante desde 1932.

Las autoridades eclesiásticas hicieron eco de esta demanda de los grupos de poder durante más de cinco décadas. Así, mientras que a nivel pastoral extensas zonas del agro salvadoreño no tuvieron una atención adecuada (que muchas veces fue inexistente), a nivel doctrinario se propagó una interpretación extremadamente conservadora (interiorista y piadosa) del mensaje cristiano. Los ejes de esta interpretación eran, primero, que los fieles tenían que preocuparse, ante todo, por la salvación de su alma, lo cual suponía llevar una vida moral recta; y, segundo, que los fieles tenían que aceptar y respetar el orden (político, económico y social) como un designio divino. En lo político, este designio era sancionado religiosamente con un Te Deum organizado por la jerarquía eclesial para bendecir el inicio de cada nuevo gobiemo ${ }^{15}$. En lo económico, los nexos de las autoridades eclesiásticas con los grupos dominantes eran estrechos; y los mismos se hacían sentir no sólo en las prebendas económicas que estos grupos ofrecían a la Iglesia, sino en las presiones en favor o en contra de una determinada orientación eclesial ${ }^{16}$.

Hacia finales de la década de los años cincuenta, la opción eclesial tradicional comienza a sufrir una serie de modificaciones, inducidas no sólo por el influjo del ambiente generado por las discusiones y los preparativos del Concilio Vaticano II -a la que no son ajenos sectores importantes del clero salvadoreño, entre los que destacan los jesuitas-, o por el influjo del compromiso de muchos cristianos latinoamericanos simpatizantes de la revolución cubana, sino por factores endógenos, socioeconómicos, políticos y religiosos, que exigen a la institución eclesial replantearse su pastoral social. Estos factores son los siguientes: $(a)$ la exclusión política de importantes sectores de la sociedad civil, incompatible con el modelo económico de carácter desarrollista que impulsa la burguesía industrial; (b) el atraso y la marginación campesinas que, de no ser atendidas, anuncian un conflicto de incalculables consecuencias; y $(c)$ la escasa o nula atención eclesial a la población mayoritaria del país que se confiesa católica, y que amenaza con desbordarse hacia el protestantismo. 


\subsection{Opción preferencial por los pobres y reacción conservadora}

Durante la década de los años sesenta, la Iglesia católica salvadoreña busca acercarse eficazmente al campo. Y lo hace promoviendo formas de organización cooperativa ${ }^{17}$. El promotor de esta pastoral de inserción eclesial en el campo es el entonces Arzobispo de San Salvador, Mons. Luis Chávez y González. Hasta finales de la década, esta orientación pastoral va a estar caracterizada en lo esencial por el asistencialismo ${ }^{14}$. Sin embargo, a fines de los años sesenta y principios de los años setenta, el modo de enfocar el problema de la organización campesina irá cambiando hasta transformarse en algo totalmente alejado de los planteamientos tradicionales. Este viraje eclesial estará muy condicionado - y de algún modo responderá- a los retos que lanza a la Iglesia católica salvadoreña el Episcopado Latinoamericano reunido en Medellín, en 1968.

Así, el compromiso eclesial, entre los años sesenta y setenta, transita -fundamentalmente en la Arquidiócesis de San Salvador- desde un apoyo a la organización campesina de naturaleza asistencial (que se expresa en el fomento de asociaciones cooperativas) hacia el compromiso decidido de sacerdotes, religiosas y religiosas y del propio Arzobispo de San Salvador, en respaldo de las demandas autónomas (sociales, económicas y políticas) de las organizaciones campesinas $^{19}$. Expresión pastoral y doctrinal de este compromiso del Arzobispado de San Salvador es la Tercera Carta Pastoral de Mons. Romero ${ }^{211}$, titulada La Iglesia y las organizaciones populares. En este documento eclesial, el Arzobispo de San Salvador no sólo defiende doctrinal y pastoralmente -argumentando desde el Vaticano II y Medellín- el derecho constitucional a la organización de los campesinos, sino que afirma que el apoyo a la misma es una tarea eclesial de primera importancia ${ }^{21}$.

Por supuesto que no toda la Iglesia católica del país responderá a los retos de Medellín, e incluso sus sectores importantes de la jerarquía eclesial —incluido el propio Mons. Romero en la primera fase de su labor sacerdotal y episcopal, en la que está más cerca de los planteamientos eclesiales tradicionales que de la pastoral de Mons. Chávez y González ${ }^{22}$-, organizados en la Conferencia Episcopal de El Salvador (CEDES), sostendrán una franca oposición a los cambios suscitados por Medellín.

Como señala Rodolfo Cardenal, "el año de 1970 fue muy importante para la Iglesia salvadoreña y particularmente para Tilo [el autor se refiere a Rutilio Grande, a quien sus amigos llamaban Tilo]. A lo largo de ese año se sintió el impacto de los documentos y las conclusiones de Medellín. Toda la Iglesia entró en una profunda crisis. La aguda lucha ideológica desencadenada, dentro y fuera del medio eclesiástico, obligó a repensar todo. Hasta entonces el clero salvadoreño se volvió hacia el Vaticano II el cual había pasado desapercibido"2?.

Como hemos dicho, no toda la Iglesia católica asume los desafíos en tomo a la nueva evangelización que Medellín promueve ${ }^{24}$, pero una buena parte de ella 
-cercana a la Arquidiócesis de San Salvador, dirigida hasta 1977 por Mons. Chávez y González y desde ese año hasta el 24 de marzo de 1980 por Mons. Oscar A. Romero- sí lo hace; y lo hace con una determinación que pronto comienza a provocar el resquemor no sólo del gobierno y de los sectores económicamente dominantes, sino de sectores importantes de la jararquía eclesial ${ }^{25}$. Como ejemplo de la reacción de estos sectores de la jerarquía eclesial, se puede traer a cuenta la "Declaración de cuatro Obispos de la Conferencia Episcopal de El Salvador", en la que los mismos manifiestan su crítica y rechazo tanto a la orientación política de las organizaciones FECCAS-UTC, como a cualquier tipo de compromiso de miembros de la Iglesia con aquéllas.

Entre otras cosas, la "Declaración" dice lo siguiente:

la Federación Cristiana de Campesinos Salvadoreños (FECCAS), nació como organización reivindicadora (sic) de los derechos de los campesinos; pero muy pronto, al derivar al campo político, buscando la toma del poder y al coaligarse con la Unión de Trabajadores del Campo (UTC); y, sobre todo, al afiliarse con el Bloque Popular Revolucionario (BPR), se declararon ambas seguidoras de la ideología marxista-leninista. La actitud proselitista de dichas organizaciones se infiltró en algunos grupos de fieles de la Iglesia, creando confusión entre los católicos y un serio problema de conciencia... Nosotros los Obispos, en cumplimiento de Nuestro Ministerio Pastoral, declaramos que las organizaciones de tipo político y de tendencia izquierdista conocidas como Federación Cristiana de Campesinos Salvadoreños (FECCAS) y Unión de Trabajadores del Campo (UTC) no son organismos de la Iglesia y, por consiguiente, no tienen derecho a reivindicar para sí la protección de la Iglesia o quererla instrumentalizar para sus fines. Los sacerdotes y religiosas que dirigen centros educativos y comunidades parroquiales debe abstenerse de colaborar directa o indirectamente con FECCAS y UTC y con cualesquiera otras organizaciones similares, cuya actividad se desarrolla en el campo directamente político (la toma del poder), y porque, además, son organizaciones de izquierda. Los seglares católicos, responsables de llevar el Mensaje de Cristo al campo social, político, cultural, eviten valerse para su obra evangelizadora de las organizaciones FECCAS y UTC ${ }^{2 n}$.

Y como ejemplo de la reacción de la oligarquía es ilustrativo el comunicado emitido en el periódico La Prensa Gráfica por el Frente de Agricultores para la Región Oriental (FARO), el 31 de marzo de 1977. En el mismo se cita el siguiente fragmento de la misa tenida el domingo 22 de marzo, en la Catedral de San Salvador:

La Iglesia cree en Dios, Creador, en Jesucristo Redentor y en Espíritu Santo Santificador. La Iglesia cree QUE EL MUNDO ESTÁ LLAMADO A SER SOMETIDO A JESUCRISTO POR UNA PAULATINA INSTAURACIÓN DEL REINO DE DIOS. Cree la Iglesia en la Comunión de los Santos y en el 
amor que une a los hombres. CREE EN EL REINO DE DIOS COMO PROGRESIVO CAMBIO DEL MUNDO DEL PECADO EN MUNDO DE AMOR Y JUSTICIA, que comienza YA en este mundo y tiene su cumplimiento en la eternidad.

Inmediatamente después de citado este texto, el documento del FARO hace el siguiente señalamiento:

FARO no tiene la intención, igual que otras veces, de incurrir en discusiones teológicas como serían: si es válido CREER EN EL HOMBRE, EN EL SOMETIMIENTO DEL MUNDO A JESUCRISTO Y EN EL PROGRESIVO CAMBIO DEL MUNDO, COMO UN CREDO, COMO UN DOGMA, EN IGUALDAD DE CATEGORÍA QUE EL DOGMA DE DIOS PADRE, DE CRISTO HIJO ÚNICO DE DIOS Y DEL ESPÍRITU SANTO, porque esas CUESTIONES DE LA FE corresponden a las más altas autoridades eclesiásticas que están en ROMA.

En Cambio, FARO tiene derecho a hacer pública su INDIGNACIÓN Y HACER VER A TODOS LOS CATÓLICOS QUE UNA ORACIÓN TAN IMPORTANTE COMO ES EL “CREDO” HA SIDO SUSTITUIDA POR OTRA NETAMENTE POLÍTICA-SOCIAL, PUES ESTE ES EL VERDADERO SIGNIFICADO DEL CONTENIDO DEL “NUEVO CREDO”. FARO le dice "NO" al Señor Arzobispo [se refiere a Mons. Óscar A. Romero], NO ADULTERE LA RELIGIÓN, SUS ORACIONES FUNDAMENTALES, SU DOGMÁTICA. Y a la vez pide a Roma su intervención para que TERMINE ESA LABOR POR POLITIZAR LA RELIGIÓN E IGLESIA CATÓLICAS ${ }^{27}$.

Finalmente, en un volante anónimo, la reacción de los sectores dominantes se manifiesta con mayor virulencia. El volante está encabezado con la siguiente frase: "Romero celebra misa-mitin", y a continuación dice lo siguiente:

El Arzobispo de San Salvador Amulfo Romero, que preside en estos momentos la Iglesia política, celebró una misa mitin, en corredores y patios del Colegio María Auxiliadora de San Salvador, el 9 de julio de 1977. Romero, que antes era sacerdote católico, pero ahora actúa como agitador profesional, haciéndoles el 'cachete' ["hacer el cachete": expresión popular salvadoreña que significa hacer una favor] a las organizaciones marxistas... EXPRESÓ QUE LA IGLESIA ES PERSEGUIDA, pero no dijo que 'su Iglesia política' ahora protege a organizaciones marxistas incluyendo a los 'pobres perseguidos de las FPL'...

Habló de los documentos de Medellín, donde cierto grupo de Obispos de vocación equivocada, decidieron que la orientación espiritual del hombre era muy aburrida y que sería mejor lanzarse a la corriente mundana. El único problema para estos buscadores de placer y de aventuras es que en la coriente mundana nadan peces de otras especies, tales como los 'UGB' que 
los pueden devorar, al encontrarlos fuera de sus conventos ${ }^{28}$. [UGB $=$ Unión Guerrera Blanca, grupo paramilitar (escuadrón de la muerte) que efectuó gran número de acciones terroristas (ajusticiamientos, desapariciones, amenazas, etc.) contra religiosos y religiosas, maestros, estudiantes, campesinos y obreros vinculados al movimiento popular.]

Con todo, sectores importantes de la Iglesia católica asumieron el desafío lanzado por Medellín. De un modo especial, los jesuitas fueron promotores decididos de esta nueva evangelización, desde la que se fomenta la inserción eclesial en el campo desde la opción preferencial por los pobres. Uno de los principales promotores jesuitas de ese compromiso fue, sin duda alguna, el P. Rutilio Grande ${ }^{20}$, quien sostuvo que la Compañía de Jesús no debía cerrarse "narcisísticamente sobre sí misma, algo que ni siquiera dice bien y es herético afirmarlo de la Iglesia Universal, cuya misión es ser servidora"3.1. En la perspectiva del P. Grande: "tanto la Iglesia como la Compañía debían identificarse y encamarse en las grandes mayorías 'tomando partido por los más pequeños a fin de que sean evangelizados integra y radicalmente para que ellos mismos sean agentes de su propio destino... De lo contrario seguiremos siendo colonizadores, cuando no dominadores en una u otra forma, a estilo de las minorías nativas, ja estilo gringo o a estilo europeo!'”'!.

\subsection{La conversión religiosa}

La opción preferencial por los pobres, en las condiciones particulares del agro salvadoreño, cobró un perfil socio-religioso y político que hizo de la misma una experiencia inédita de vida cristiana en América Latina. En el marco de dicha experiencia, grupos importantes de campesinos salvadoreños hacen suyo -animados por sacerdotes, religiosas y delegados de la palabra que han asumido el reto de traducir las enseñanzas de Medellín a la realidad salvadoreña- el evangelio del Jesús histórico, es decir, del Jesús que se solidariza con los oprimidos y que les trae la buena noticia de la liberación. El siguiente texto de la misa popular salvadoreña recoge esta lectura del evangelio desde la "periferia del mundo" (L. Boff):

Por ser justo y defensor del oprimido/Porque nos quieres y amas de verdad/ venimos hoy todo tu pueblo decidido a proclamar nuestro valor y dignidad/ Ahora señor podrás tu ser glorificado/Tal como antes allá en el Monte Tabor cuando tú veas antes a este pueblo transformado/Y haya vida y libertad en $\mathrm{El}$ Salvador/Los dioses del poder y del dinero se oponen a que haya transfiguración/Por eso ahora Señor sos vos el primero en levantar tus brazos contra la opresión ${ }^{32}$.

Como podemos ver, estamos ante una nueva lectura de lo que Dios quiere para los desposeídos; no quiere ni la resignación piadosa ni una fe sin compro- 
miso. Estamos ante una interpretación religiosa que ve a Dios como un Dios contrario a la opresión y a la marginación, es decir, un Dios comprometido con la vida y la libertad. En Aguilares es en donde con mayor nitidez se hizo presente esta "nueva lectura" del mensaje cristiano. Esta zona rural —en la perspectiva de los sacerdotes y religiosos involucrados con la opción preferencial por los pobres y la teología de la liberación- era clave para una nueva experiencia pastoral porque expresaba las múltiples contradicciones que aquejaban al agro salvadoreño. En 1972 -señala C. R. Cabarrús-, estos sacerdotes y religiosas se lanzan a la tarea evangelizadora, misma que supuso la inserción, durante casi un año, de aquellos en los diversos cantones, así como su convivencia con la población campesina, "comiendo lo que se les daba, aceptando cualquier incomodidad para construir la comunidad desde abajo y no por imposición"33. De este modo, la misión logró, "estructurar la masa campesina y urbana cohesionando la gran comunidad en comunidades dirigidas o más bien animadas por un grupo en el que prevalecen unos hombres dirigidos por la comunidad al final de la misión: son los 'delegados'. No era propiamente una directiva, porque de cada cuatro o cinco personas se elegía un delegado, y pudieron llegar a ser hasta 15 ó 20 delegados por comunidad. En total fueron 300 delegados los que aceptaron como principio el que todo cargo debe ser mirado como servicio y no como dominación, a fin de buscar con los demás 'la verdad, la unión, la acción, la organización', como decían"’3.

En estas comunidades, animadas en un principio por los sacerdotes y posteriomente por los delegados de la palabra, se lee el Evangelio a la luz de la situación real que viven cotidianamente los campesinos. Como señala Cabarrús, "los ojos de la gente se abren al Evangelio y aprenden a unirlo con su situación, a 'traerlo de lo espiritual a lo material', según manifestaban. Despiertan a la conciencia de que la situación de opresión en que viven no es voluntad de Dios y de que muchos males vienen 'por no ser unidos'. Comienzan a reunirse, a movilizarse y a ver qué es lo que pueden hacer. La meta pretendida por el equipo misionero es la de 'realizar una comunidad de hermanos comprometidos a construir un mundo nuevo sin opresores ni oprimidos, según el plan de Dios'”3.3.

Progresivamente, esta dinámica pastoral fue posibilitando una mutación religiosa en la conciencia de los campesinos involucrados en el proceso. Cabarrús, quien vivió directamente este proceso, sostiene que "antes de la llegada de las misiones con las que se abrió el trabajo pastoral, el mundo 'religioso' del campesino de Aguilares estaba caracterizado por las típicas notas de una ideología religiosa campesina, es decir, enmarcadas en un sistema por el cual el campesino es explotado por el capital, pero él mismo es el agente directo de dicha explotación. Esto lo hace mistificar esa explotación que casi no percibe ni por la vía del salario, ni por la vía del precio de los productos, ni por la renta de la tierra. Debe agregarse la misma trabazón con lo 'rural' y con la agricultura, que imprime un carácter peculiar a su manera de pensar y valorar: los códigos interpretativos hacen siempre relación con las estaciones y las cosechas"”. 
Así, para un campesino de Aguilares: "con la misión hubo un cambio. Desde la misión, en los quince días hubo una gran movilización; bajaba gente de todas partes a Areditas. Entonces hubo una gran movilización y quedó la cosa más en orden. Se formaron grupos de delegados que decían que habían unos explotadores y otros explotados. Se comenzó a descubrir la situación real. De ahí vimos la necesidad de ir protestando, aunque no nos habíamos organizado ni nada... vimos que no era que no era simplemente necesario la organización, sino una verdadera urgencia. Allí comenzó a meterse la organización en la zona" ${ }^{37}$.

Pero, con el trabajo de la misiones, la religiosidad campesina, como ya lo señalamos, se va transformando progresivamente. La idea de Dios como causa única e irreversible de los acontecimientos es lentamente reemplazada por la idea de un Dios que actúa en la historia no a espaldas de los hombres, sino a través de éstos. Es esto lo que aparece con claridad en el siguiente testimonio de un campesino de Aguilares: "yo creo en un Dios de justicia y amor y paz, y no en un Dios que esté en las nubes, que está en el corazón de los explotadores, en un Dios de la explotación, en un Dios convertido en pisto (dinero), en un Dios convertido en propaganda, ni en un Dios que se le agrade con cohetes, ni con ceremonias tradicionales"...

En definitiva, en la conciencia de estos campesinos se gesta un proceso de conversión religiosa que los llevó, de una visión religiosa cunsi fatalista, hacia una visión religiosa "liberadora", en el sentido de haberles hecho pensar a Dios como un Dios de justicia y de libertad. Como lo sintetiza T. S. Montgomery: "el nuevo mensaje era: 'Dios es un Dios de justicia que actúa en la historia a favor de los pobres y oprimidos. La pobreza de ustedes no es voluntad de Dios... De la misma manera que Moisés y los israelitas asumieron el reto de su liberación, ustedes tienen derecho para asumir la responsabilidad de su propia liberación... Y la Iglesia tiene la obligación de acompañarlos en el proceso"39.

Esta visión del cristianismo -que no llama a la resignación piadosa, sino a la rebelión comprometida - pronto cuaja en una forma organizativa que será decisiva para la evolución posterior del movimiento popular campesino: las Comunidades Eclesiales de Base (CEBs), que se expanden en las zonas más pobres del campo salvadoreño y en los barrios y colonias populares de diferentes ciudades". En esas comunidades se forjan, mediante la lectura "teológica" de los problemas concretos que aquejan a la comunidad, muchos líderes religios laicos. Estos, como delegados de la palabra, multiplican el nuevo mensaje cristiano por los diversos cantones y caseríos del campo salvadoreño, especialmente en la zona de Aguilares (al norte de San Salvador) ${ }^{4}$, Chalatenango y Morazán (en la zona norte y nororiental del país, respectivamente).

De esta forma, como dice T. S. Montgomery: "para los campesinos, a quienes nunca se les había pedido pensar y a quienes mucho menos se les había preguntado lo que pensaban, las Comunidades Eclesiales de Base fueron, al menos, 
una experiencia concientizadora"42. A lo anterior, Cabarrís añade lo siguiente: "el deterioro de la vida campesina y la ruptura de las reglas de juego de articulación de ésta con el capitalismo salvadoreño, preparó las condiciones para que se pudiera trabajar con éxito en una evangelización (liberadora)"'s.3, es decir, en la predicación de la Buena Nueva del Reino.

\subsection{De la conversión religiosa a la conversión política}

Esta evangelización pronto reveló sus implicaciones políticas. $Y$ es que, en el marco de la violencia estructural sufrida por los campesinos salvadoreños, la nueva fe planteaba tareas bien concretas, que tenían que ver directamente con el problema de la concientización y la organización política. Los campesinos involucrados en el proceso así lo entendieron: asumieron la lucha por su dignidad dándose formas organizativas apropiadas para ello ${ }^{44}$. Enseñar a los campesinos a vivir la fe de una forma emancipadora: este fue el logro más importante de las comunidades eclesiales de base. Esto supuso que los campesinos emergieran de su pasividad y se asumieran como sujetos de su destino, con el derecho y el deber de participar en la construcción de una sociedad más justa y solidaria, en la que ellos y sus hijos pudieran vivir dignamente. Se operó en la conciencia campesina una conversión religiosa. La religión, de ser "opio del pueblo", se convirtió en un elemento movilizador y subversivo. Las bases estaban puestas para que esa conversión religiosa se transformara en una conversión política.

El proceso de conversión religiosa supone la transición de una religiosidad tradicional, anclada en una vivencia de fe interiorista y piadosa, hacia una religiosidad comprometida socialmente. Este proceso de conversión religiosa se da al interior del catolicismo, es decir, no supone la migración hacia otro universo religioso por parte de los creyentes. Asimismo, el proceso es dinamizado por un cambio de referentes simbólico-religiosos que opera en la subjetividad de los actores involucrados ${ }^{45}$, posibilitado ese cambio de referentes por una nueva interpretación y lectura del mensaje cristiano. El trabajo eclesial en el campo es, precisamente, la instancia que articula ese proceso de concientización, con el cambio de valores y de opciones vitales que ello trae consigo. A su vez, hay un "entomo ecológico" (Gilberto Giménez) determinado, en el que sectores populares campesinos realizan su existencia, que se convierte en un factor coadyuvante del proceso de conversión religiosa que se operó en la conciencia de importantes sectores del campesinado salvadoreño.

Esta mutación religiosa no sólo supuso un cambio de valores, sino que trajo consigo, allí donde se operó, un cambio generacional en los liderazgos religiosos de la comunidad. El análisis de la experiencia de Aguilares lleva a Rodolfo Cardenal a sostener lo siguiente: "en efecto, el liderazgo religioso pasó a la población joven de la parroquia. En realidad, los jóvenes asimilaron primero el método y las nuevas ideas religiosas. Esto creó cierto conflicto de poder con los 
antiguos adoradores, quienes habían mantenido el liderazgo religioso hasta entonces. Pero poco a poco comprendieron que por su edad los jóvenes estaban mejor capacitados para desempeñar las nuevas tareas limitándose ellos a aconsejar desde la experiencia y la edad. Por otro lado, se sintieron profundamente satisfechos al ver cómo los jóvenes entraban por los caminos de Dios"4h.

Pero el proceso de conversión religiosa (intrarreligiosa) no se agota en sí mismo. En las condiciones históricas (sociales, económicas, culturales y políticas) en que el mismo tiene lugar -y por las propias potencialidades intrínsecas del proceso de conversión religiosa - el tránsito hacia una conversión política deja de ser una posibilidad y se convierte en una realidad. Es así como los líderes religiosos laicos - no sin tensiones con los miembros de los equipos pastorales de la Igle$\mathrm{sia}^{47}$, se convierten en organizadores y dirigentes políticos. Se opera un proceso de conversión religiosa en conversión política. Ciertamente, la una no supuso el abandono de la otra; ni tampoco el haber alcanzado la primera supuso inexorablemente el alcance de la segunda. Sin embargo, donde ambas coexistieron, se potenciaron mutuamente. Más aún, no fueron dos cosas distintas: los individuos que las vivieron, sin dejar de ser creyentes - y justamente porque lo eran- pasaron a ser dirigentes y organizadores de sus comunidades ${ }^{44}$. "La inmensa mayoría de los miembros de las organizaciones populares - señala Jesús Delgado- eran cristianos; pocos, muy contados, eran los que por prurito intelectual se preciaban de ateos y sin religión. Muchísimos hombres y mujeres de entre ellos habían aprendido a descubrir su propia situación como situación de pecado y de injusticia en las comunidades eclesiales de base. Allí se motivaron a la luz de la palabra de Dios y allí maduraron hasta descubrir ellos mismos, como laicos, la necesidad de un compromiso de índole política que les permitiera concretar las aspiraciones justas de su liberación" ${ }^{4}$. "La experiencia política -dice Cabarrúses también fe profunda; se llega a político porque se cree". Este es el núcleo de la fuerza que va a adquirir el movimiento campesino posterior. "De no haber sido así - continúa Cabarrús - el apremio campesino hubiese podido conducir a la anarquía y al caos, cuyos derroteros finales hubieron podido ser milenarismos o desperdigamiento del movimiento que se gestaba"si".

Por otra parte, si la conversión religiosa supuso la aceptación de una nueva religiosidad por parte de los campesinos, la conversión específicamente política supuso la aceptación de unos credos políticos determinados. El más importante de ellos fue, sin duda alguna, el de la organización. Porque para los campesinos que habían asumido el desafío del Jesús comprometido con su liberación, ese desafío no se agotaba en un compromiso religioso, sino que debía manifestarse en el compromiso organizado y revolucionario. Es decir, se tenía que pasar de lo religioso a lo político. Esto se expresa en el siguiente testimonio:

yo entré a la organización cuando vi lo que realmente me iba aclarando al oír esas cosas. Cuando desperté y vi que se necesitaba un cambio. Porque yo 
creo que desde el momento en que uno se compromete, se decide, así, es posible que le quede el pellejo en donde quiera que sea. Uno ya sabe que es la lucha de su pueblo. Y si no le entramos como a la lucha del pueblo de uno, y si no le tenemos amor a nuestros hijos ni a las futuras generaciones que vengan, no se hace eso. Sólo eso es lo que nosotros podemos dejarles de recuerdo.

Esa es la lucha que nosotros hemos comenzado. Si nosotros no podemos ver el cambio, tal vez nuestros hijos sí lo van a completar. Yo por eso me metí en la organización.

La mayor parte de compañeros están claros ya, de cuál es el papel que jugamos en la organización y sienten eso bonito; jes que hay gente bien inteligente! No podemos decir que nosotros somos los líderes del cantón y que ya lo movilizamos. No, hay gente que tiene el sentido más profundo de la revolución que uno. Desde el momento que se dice: soy afiliado, ya hasta hablamos de la revolución porque estamos hablando de un cambio. Y por lo menos empezamos a dejar los vicios y estamos colaborando en el sentido de que estamos siendo ejemplo para los demás. Y los demás, que lo han visto a uno en esa situación, ven el ejemplo ${ }^{51}$.

Pero también hicieron su aparición otros referentes políticos, como por ejemplo el de "socialismo" y "toma del poder": "el socialismo - dice otro campesino- es una sociedad que se va a vivir ya como hermanos, que ya no se va vender barata la mano de obra, que va a haber siquiera más comida y más alimentación y más ropa y calzado; eso es el socialismo. Lo que va a hacer que haga ( $\mathrm{sic}$ ) socialismo es luchar organizadamente. La toma del poder es la que no costará mucho; la mantenida de ese poder eso sí que nos va a costar"s2.

Pues bien, los frutos de este proceso de conversión religiosa y política no tardaron en hacerse sentir. La Federación Cristiana de Campesinos Salvadoreños (FECCAS), fundada en 1969 como una asociación de ligas campesinas ${ }^{53}$, resurge en Aguilares a mediados de los setenta "como la más fuerte organización campesina" (C. R. Cabarrús), mientras que en Usulután y Chalatenango se funda la Unión de Trabajadores del Campo (UTC) que, nacida del trabajo pastoral, pronto deriva su accionar hacia el terreno político. Ambas organizaciones entran en contacto en 1975 y se articulan en la Federación de Trabajadores del Campo (FTC), la organización campesina más fuerte que ha conocido la historia del país. A lo largo de ese año, esta organización establece nexos con ANDES 21 de Junio (la organización de los maestros salvadoreños), con las Fuerzas Universitarias Revolucionarias 30 de Julio (FUR-30), con los Universitarios Revolucionarios 19 de Julio (UR-19), con la Unión de Pobladores de Tugurios (UPT) y con el Movimiento Estudiantil Revolucionario de Secundaria (MERS). El 5 de agosto de 1975 nace el Bloque Popular Revolucionario (BPR), como un frente popular de masas que "aseguraba al movimiento miras más amplias y aporte 
teórico distinto, pero enraizado en las masas campesinas, prestas a desfilar por las calles de San Salvador, conscientes de su fuerza y sabiendo que se puede nadar contra la corriente cuando el río es todavía pequeño, pero que nadie puede lograrlo cuando se vuelve poderoso"s4.

Los orígenes de FECCAS — cuando daba sus primeros pasos como una liga campesina - estuvieron marcados por demandas eminentemente reivindicativas. La organización era pensada "como una organización donde los miembros estudiarían para 'capacitarse' y pasar entonces a formar parte de los sindicatos o de la lucha por la formación de los mismos"ss. Progresivas transformaciones organizativas, a las que se suman los procesos de conversión religiosa y política vivido por muchos de sus miembros y dirigentes, hacen posible que hacia mediados de los años setenta la organización - sin dejar de lado las demandas estrictamente reivindicativas ${ }^{5 h}$ - haga eco de demandas políticas de alcance estructural. Cuando esto sucede, FECCAS ya se autodefine desde una perspectiva revolucionaria. Como sostiene un campesino miembro de la misma: "nuestra organización de ninguna manera puede quedarse en la lucha por las demandas inmediatas, que es una lucha por la subsistencia. Con ella no se alcanzará el fin de la explotación ni se resolverán, en consecuencia, los problemas fundamentales de los trabajadores del campo. Para terminar definitivamente con la explotación capitalista, FECCAS plantea la urgente necesidad de que los jomaleros y campesinos pobres se incorporen a la Lucha Revolucionaria, objetivo que se alcanzará ligando correctamente la lucha por las necesidades inmediatas a la lucha por las necesidades fundamentales" 57 .

Uno de los momentos cumbres de la radicalización de la conversión política campesina lo constituye la vinculación, primero, de FECCAS con la UTC - vinculación de la que surge la Federación de Trabajadores del Campo (FTC)-, y, segundo, la articulación de éstas con el Bloque Popular Revolucionario. Su vinculación en tanto que organizaciones campesinas los lleva a sostener que "con un accionar revolucionario consecuente, representamos y defendemos los intereses inmediatos y fundamentales de la clase trabajadora del campo". Mientras que su articulación con el BPR es definida como una alianza estratégica que ha de conducir "a la consolidación de un Frente Revolucionario de Masas, basado en la alianza obrero-campesina con hegemonía proletaria, conscientes de que esta es la vía real... para terminar de una vez para siempre con este sistema de explotación e injusticia y construir una sociedad cuyas columnas sean la solidaridad, la igualdad y la paz"sy.

Más aún, en la medida en que FECCAS-UTC consolidan su compromiso político-revolucionario - es decir, en la medida en que la conversión política de sus miembros se radicaliza-, se genera un proceso de deslindamiento respecto de los vínculos eclesiales que posibilitaron su surgimiento. "FECCAS-UTC —se lee en un pronunciamiento emitido en 1978- somos organizaciones completa- 
mente independientes de la Iglesia católica. No es requisito para pertenecer a nuestra organización ser cristiano. Sin embargo, muchos de los que militan en ella lo son, ya que gran parte de los jornaleros y campesinos pobres de nuestro país lo son"sy.

Entre 1975 y 1979, el movimiento popular salvadoreño cobra un nuevo impulso y nuevas perspectivas al sumarse a las actividades del BPR, el accionar del Frente de Acción Popular Unificada (FAPU) ${ }^{(n)}$, fundado en $1974^{\left({ }^{(11}\right.}$, las Ligas Populares 28 de Febrero (LP-28) ${ }^{\text {h2 }}$, fundadas en 1977 y el Movimiento de Liberación Popular (MLP) ${ }^{63}$, constituido en 1979. A lo largo de este período, el movimiento popular organizado se convierte en un actor fundamental de la dinámica social y política en El Salvador ${ }^{\text {H. }}$.

A medida que se acrecienta la lucha popular - -que se expresa en movilizaciones de calle, toma de locales públicos e iglesias, así como por tomas de propiedades agrícolas-, la represión gubernamental se agudiza. Por otra parte, paralelamente al crecimiento y a la consolidación del movimiento popular, las organizaciones político-militares se han fortalecido y se han consolidado internamente, no sólo a nivel de sus estructuras organizativas, sino a nivel político e ideológico. En El Salvador —entre 1970 y 1975 — han madurado una serie de condiciones que hacen factible la vinculación entre el movimiento guerrillero y el movimiento popular organizado. Como señala Cabarrús: si la rebelión se estructura entre 1975 y 1977, entre 1977 y 1980 la rebelión se arma.

\section{Organizaciones populares y organizaciones político-militares}

Paralelamente al crecimiento y a la consolidación del movimiento popular, se fortaleció otro grupo de actores presentes en el quehacer sociopolítico de los años setenta: las organizaciones político-militares. Estas organizaciones, formadas por miembros radicalizados de las clases medias -especialmente por estudiantes y profesores universitarios que, en cierto modo, dieron continuidad al papel protagónico de los sectores medios desde la caída del general Maximiliano Hemández Martínez y, en menor medida, por líderes sindicales-, no sólo multiplicaron sus acciones militares - secuestros de empresarios, hombres de negocios y diplomáticos, ataques a puestos militares, quemas de vehículos automotores-, sino que dieron inicio a un proceso de acercamiento a las organizaciones populares, de las cuales comenzaron a reclutar a nuevos cuadros guerrilleros.

Los lemas de estos grupos expresaban bien su determinación a llevar hasta las últimas consecuencias la lucha por la transformación revolucionaria en El Salvador. Fuerzas Populares de Liberación Farabundo Martí (FPL): "Revolución o muerte. El pueblo armado vencerá". Ejército Revolucioanrio del Pueblo (ERP): "Vencer o morir". Fuerzas Armadas de la Resistencia Nacional (FARN-RN): "Lucha amada hoy, socialismo mañana". Partido Revolucionario de los Traba- 
jadores Centroamericanos (PRTC): "Combatir hasta vencer por Centroamérica, la liberación y el socialismo".

Entre 1977 y 1980, las organizaciones político-militares y el movimiento popular organizado establecen vínculos orgánicos, posibilitados por la lucha reivindicativa y política que el segundo impulsa en casi todo el territorio nacional. Esa lucha, que en rigor es una práctica política popular, constituye justamente el punto en que las organizaciones populares de procedencia cristiana pueden confluir con las organizaciones guerrilleras. La matriz simbólica de cada una es distinta, pero el compromiso político por ellas asumido (compromiso al que se ha llegado por motivaciones distintas), los lleva a confrontarse con los mismos enemigos y les plantea le necesidad de vincularse y potenciarse mutuamente. De este modo, cada organización guerrillera establece nexos con un frente de masas determinado ${ }^{\text {h5 }}$. Así, las FPL se articulan con el BPR, el ERP lo hace con las LP28, las FARN lo hacen con el FAPU y el PRTC lo hace con el MLP. Por su parte, las FAL redefinen sus relaciones con la Unión Democrática Nacionalista (UDN) $^{\text {sh }}$ que, de partido político, se convierte en un frente de masas. Se trata de un vínculo político que se establece en la medida en que los núcleos guerrilleros se van convirtiendo en el mecanismo de autodefensa que utilizan las organizaciones populares cuando son agredidas por los cuerpos de seguridad.

Por su parte, a nivel organizativo, se genera un proceso de fortalecimiento de los grupos político-militares vía la incorporación de miembros y dirigentes de las organizaciones populares, especialmente de miembros de las organizaciones campesinas, no sólo a sus estructuras de base, sino a sus organismos de dirección, con lo cual se insinúa y posibilita una dinámica de conversión ideológica en el seno mismo de las organizaciones político-militares ${ }^{\text {h7 }}$.

Es claro que la militancia guerrillera ofrece a los nuevos cuadros elementos de análisis diferentes a los de su matriz cristiana, con lo cual se modifica en muchos aspectos su visión de la realidad nacional. Pero la influencia también va en sentido opuesto: ellos influyen en la visión política - y sobre todo humanade los militantes no cristianos. De este modo, se establecieron las bases de un proceso de enriquecimiento mutuo, cuyos frutos más palpables se tradujeron en la enorme fuerza y creatividad del movimiento popular salvadoreño durante la segunda mitad de la década de los años setenta.

En definitiva, los grupos político militares, desde una matriz ideológica marxista-leninista, no sólo hicieron eco de las ideas de cambio social difundidas a partir de la revolución cubana de 1959 - rompiendo, así, con el acomodamiento socio-político del PCS, que básicamente se había resignado a participar en el juego electoral一, sino que justificaron su irrupción apelando tanto a la pobreza crítica en que vivían la mayor parte de salvadoreños - la pobreza estructuralcomo a la exclusión política de la que hacían gala los gobiernos militares. Integrados en su mayoría por jóvenes radicalizados de los sectores medios, los gru- 
pos político militares - una vez que consideraron que las vías legales para acceder al poder estatal se habían agoptado- optaron por la lucha revolucionaria como mecanismo idóneo para enfrentar a los regímenes militares, primero, del coronel Molina; después, del general Romero; y, ya en los años ochenta -cuando se aglutinaron en el FMLN - a la Junta Revolucionaria de Gobierno, al gobierno de Napoleón Duarte (1984-1989) y, al cierre de la década de los ochenta y principios de la década de los noventa, al gobierno de Alfredo Cristiani.

\section{Balance final}

La década de los años setenta se cierra en El Salvador con una grave crisis política. El gobiemo del general Carlos Humberto Romero, por más que puso en marcha medidas como la "Ley de defensa y garantía del orden público" - inspirada en la Doctrina de la Seguridad Nacional que los gobiemos militares suramericanos habían implementado para contener la participación socio-política de amplios sectores de la sociedad- fue incapaz de controlar el desborde de las organizaciones populares. El 15 de octubre de 1979, un grupo de militares progresistas realizó un golpe de Estado, con pretensiones reformistas, que fue cooptado por militares conservadores. Mientras tanto, las organizaciones populares radicalizaron sus demandas y, como consecuencia de ello, tuvieron que soportar los embates de la represión estatal ${ }^{\text {try }}$.

La Junta Revolucionaria de Gobierno no pudo hacer frente a la crisis política, respondiendo a las movilizaciones de las organizaciones populares con enormes cuotas de represión estatal. Cuando José Napoleón Duarte se incorporó a la Junta, en diciembre de 1980, se iniciaron reformas económicas y sociales -reforma agraria y nacionalización de la banca y del comercio exterior-, pero se acompañaron de fuertes dosis de violencia estatal. Los líderes de las organizaciones populares percibieron que no había otro camino que optar por la insurrección revolucionaria. Esta opción se concretó en la creación, en mayo de 1980, de la Dirección Revolucionaria Unificada-Político-Militar (DRU-PM), un mando conjunto que coordinaría las actividades militares de los diferentes núcleos guemilleros y la Coordinadora Revolucionaria de Masas (CRM), que se encargaría de coordinar el trabajo político de los frentes de masas. En abril del mismo año se constituyó el Frente Democrático Revolucionario (FDR), que aglutinó a la gran mayoría de organizaciones revolucionarias y a los partidos de oposición, instituciones, gremios y personalidades democráticas del país. En octubre de 1980, la DRU se transformó en el Frente Farabundo Martí para la Liberación Nacional (FMLN). El 10 de enero de 1981 el FMLN lanza su "ofensiva final" u "ofensiva general" y se inicia formalmente la guerra civil.

Durante los doce años de conflicto armado, el FMLN desplegó todas las potencialidades forjadas durante la década anterior. Innumerables miembros de las organizaciones populares de la ciudad -muchos de ellos sobrevivientes de 
la represión desatada en el país entre 1981 y 1983 - se incorporaron a sus filas $^{\text {}}$. Lo mismo hicieron innumerables campesinos procedentes tanto de la FECCAS-UTC como de otras organizaciones campesinas, quienes no sólo pasaron a integrar las filas del ejército guerrillero, sino que se convirtieron en su base social fundamental, su fuente de abastecimiento y la garantía de su supervivencia material. En estas condiciones, militarmente el FMLN se convirtió en una guerrilla poderosa, capaz de enfrentarse a un ejército de más de 50 mil hombres, asesorado, entrenado y financiado por Estados Unidos, en un territorio de 21 mil kilómetros cuadrados, sin grandes montañas y rodeado de países con regímenes hostiles a la lucha guerrillera (Honduras y Guatemala) ${ }^{70}$.

Lentamente, el FMLN comenzó un proceso de readecuaciones internas que se tradujeron en cambios significativos en sus planteamientos estratégicos, todo lo cual no fue ajeno a la reestructuración del escenario intemacional propiciado por el derrumbe del bloque del este, así como a la nueva correlación de fuerzas que al interior del país - tras doce años de una guerra civil empantanada, el cansancio social generalizado y el fuerte impacto nacional e intemacional del asesinato, el 16 de noviembre de 1989 y por tropas del ejército, de los jesuitas Ignacio Ellacuría, Segundo Montes, Amando López, Juan Ramón Moreno, Ignacio Martín-Baró, Joaquín López y López, y sus colaboradoras Elba Ramos y su hija Celina Maricet- se impuso entre los bandos en contienda.

En ese escenario, el FMLN transitó, no sin dificultades y largos debates ideológico-políticos, de una lucha revolucionaria por el poder político del Estado a una lucha revolucionaria por la fundación de una nación en que la democracia social y política llegaran a ser los ejes axiales de la vida social, económica y política"1. Por su parte, el partido ARENA, tras dejar atrás sus antecedentes de institución vinculada a los escuadrones de la muerte a principios de la década de los años ochenta y respaldado por su ala más moderada, encaró los desafíos que planteaba una negociación del fin de la guerra con el FMLN. La ofensiva lanzada por los insurgentes, en noviembre de 1989, puso de manifiesto no sólo que un triunfo militar definitivo por cualquiera de los bandos no estaba cercano, sino que los costos económicos de la guerra hacían inviable cualquier propuesta de desarrollo económico-social. El consenso sobre este punto -al igual que la buena voluntad y el empeño puestos por las comisiones negociadoras- fue lo que desencadenó la ronda de negociaciones que culminaron, en enero de 1992, con la firma de los acuerdos de paz.

Los acuerdos de paz de Nueva York (1991) y Chapultepec (1992) constituyeron un punto de partida fundamental para el nuevo proyecto de nación, que el FMLN hizo suyo en el transcurso de los 12 años de guerra civil. También se convirtieron en el punto de partida para que el gobiemo de ARENA pudiera implementar sus planes de desarrollo económico, orientados no sólo a fortalecer el sistema financiero, sino a generar confianza entre los grupos empresariales 
nacionales e internacionales. Cuatro años después de firmados, los acuerdos de paz fueron declarados oficialmente cumplidos. No obstante, aspectos sustantivos de ellos - como la implantación de nuevas relaciones entre trabajadores, Estado y empresarios, y la democratización de los partidos políticos- quedaron pendientes y constituyen, en la actualidad, puntos medulares en la agenda de la democratización del país.

En definitiva, los doce años de guerra civil, los triunfos, las derrotas, los asesinatos, las persecuciones, el temor y la inseguridad, contribuyeron decisivamente a moderar las posturas políticas más extremas y a aceptar que si no se podía exterminar al enemigo, al menos había que intentar convivir con él. El FMLN decidió, al firmar los acuerdos de paz, competir electoralmente por una cuota de poder, siempre revocable a través de las umas, y el sistema político se abrió a las propuestas ideológicas y políticas del FMLN convertido en partido político. Este fue uno de los logros más importantes de los acuerdos, con lo cual la transición a la democracia dio un paso sin precedentes. Ahora existe un amplio consenso entre los más diversos grupos sociales y políticos de que la democracia es mejor que el autoritarismo.

Desde la década de los años setenta hasta el momento actual, se han operado importantes transformaciones en la realidad salvadoreña. La violencia sociopolítica, que abatió al país en los años setenta y se convirtió en un conflicto armado abierto en la década siguiente, dio paso a un proceso de reformas políticas de carácter democrático. Lentamente, se va construyendo un Estado de derecho, con el subsiguiente respeto a la legalidad que el mismo supone; el equilibrio de poderes, aún con limitaciones, poco a poco va permitiendo un ejercicio sin abusos del poder político. En el ámbito económico se han operado importantes cambios en la estructura productiva; El Salvador está dejando de ser un país agrícola para convertirse en un país dominado por el sector terciario. La reforma agraria de los años ochenta, la guerra civil y la implementación de una serie de reformas neoliberales por las dos administraciones de ARENA - y que al parecer continuarán siendo impulsadas por la administración de Francisco Flores- incidieron en forma decisiva en la transformación de la economía nacional. Como complemento de estos procesos de cambio económico y político, se está operando una importante reforma del Estado, la cual está encaminada a reducir el protagonismo económico que comenzó a adquirir en 1931. De un modelo económico en el cual el Estado era un actor decisivo, estamos pasando, en la década de los noventa, a un modelo económico que exige del Estado una participación mínima. El Estado salvadoreño se va acomodando, a través de su reforma institucional, a esas exigencias.

En este marco, el desafío de los años noventa —una vez que la violencia política ha sido superada - lo constituye la violencia social, cuyos brotes más llamativos (la delincuencia, los secuestros, los enfrentamientos entre pandillas 
de jóvenes, la violencia intrafamiliar) hacen que la mayor parte de la población se sienta insegura y muchos de sus miembros, alentados por diversas figuras políticas, añoren la vuelta al control y la fuerza que predominaron durante el largo reinado de los militares. En el siglo que termina, El Salvador, tras dejar atrás la violencia política que dominó la vida nacional en las dos décadas pasadas, está siendo presa de la violencia social, la cual plantea desafíos sin precedentes no sólo a las autoridades gubernamentales, sino al conjunto de la socie$\mathrm{dad}^{\text {T2}}$. Así, pues, unos de los grandes retos del país para el nuevo milenio lo constituye esa violencia social, cuya presencia está socavando los fundamentos de la convivencia entre los salvadoreños. Muchos de los esquemas culturales que propician actitudes y comportamientos violentos en la actualidad surgieron en las dos décadas anteriores. La idea de que la fuerza y la prepotencia son la mejor salida tanto para controlar a la sociedad (autoritarismo) como para cambiarla (rebeldía revolucionaria), se ha arraigado tanto en la cultura política salvadoreña que aun ahora constituye una amenaza para el avance del proceso de democratización. En este sentido, las décadas de los años setenta y ochenta están más cerca de nosotros de lo que parece y es conveniente - si queremos recuperar lo mejor de esos años y superar sus peores secuelas — no olvidarlo.

San Salvador, septiembre de 1999.

\section{Notas}

1. AAVV, El Salvador: año político 1971-72, San Salvador, Universidad Centroamericana "José Simeón Cañas", 1973, p. 78.

2. Ver L. A. González, Izquierda marxista y cristianismo en El Salvador 1970-1992 (Un ensayo de interpretación). Tesis de Maestría en Ciencias Sociales, FLACSOMéxico, junio de 1994.

3. Pera el análisis del proceso de transformación agraria, ver I. Ellacuría, "El primer proyecto de transformación agraria", en I. Ellacuría, Veinte años de historia en El Salvador (1969-1989), San Salvador: UCA Editores, Vol. I, 1991, pp. 559-566; I. Ellacuría, "Un marco teórico valurativo de la reforma agraria", en Veinte años..., pp. 567-586; I. Ellacuría, "La transformación de la ley del Instituto de Transformación Agraria", en Veinte años.... Vol. I, pp. 629-648.

4. Art. 1. "El proyecto tiene una extensión superficial de cincuenta y ocho mil setecientos cuarenta y cuatro hectáreas ( $58.744 \mathrm{Ha}$.) ubicado en las jurisdicciones de los Municipios de Jiquilisco, Ozatlán, Usulután, Santa María, Ereguayquín, Concepción Batres y Jucuarán, todos del departamento de Usulután y los municipios de El Tránsito, San Miguel y Chirilagua del departamento de San Miguel", Estudios Centroamericanos (ECA), 335-336, 1976, pp. 606-610.

5. Ver Estudios Centroamericanos (ECA), 335-336, 1976, pp. 591-606.

6. En sus artículos 21 y 27, la Ley del ISTA era clara al respecto: Art. 21. "El ISTA fomentará la organización campesina de acuerdo con su Ley y Reglamentos, especialmente para: a) facilitar en los asentamientos campesinos la prestación de servi- 
cios necesarios para la producción tales como: adquisición de insumos, servicios de maquinaria, levantamiento de las cosechas, comercialización y procesamiento de las mismas, a través de una forma asociativa; b) crear una actitud de solidaridad, en las obligaciones y riesgos de las empresas agropecuarias y forestales que se establezcan en el proyecto; c) establecer reservas específicas para invertir en el desarrollo de las nuevas actividades económicas del Proyecto, a fin de incorporar al proceso de transformación agraria a un mayor número de familias o para el mejoramiento de los servicios comunitarios que se presten a los campesinos en el área". Art. 27. Para la realización de este Proyecto, el ISTA contará con una Unidad Ejecutora, cuyas funciones serán esencialmente las siguientes: a) administración temporal de las tierras del proyecto; b) adecuación de las mismas; c) promoción, organización y capacitación campesina; y d) coordinación, en la zona del proyecto, de las actividades que corresponda ejecutar a las instituciones del Estado que participan en el mismo, de acuerdo con la programación correspondiente".

7. Este es el título de un editorial de la Revista Estudios Centroamericanos (ECA), de la Universidad Centroamcricana "José Simeón Cañas", escrito a propósito de la debilidad del gobiemo de Molina ante la derecha salvadoreña. El editorial costó a la universidad el subsidio gubernamental del que hasta el momento gozaba. Ver. "A sus órdenes, mi capital", Estudios Centroamericanos (ECA), 337, 1976, pp. 637-643.

8. Para el examen de los cambios introducidos por el decreto 123 , ver el editorial de la revista $E C A$, "A sus órdenes, mi capital", ya citado.

9. Para una caracterización del Estado liberal y del papel jugado por la Iglesia en sus relaciones con el mismo, ver R. Cardenal, El poder eclesidstico en El Salvador (1871-1931), San Salvador: UCA Editores, 1980, pp. 19-75.

10. R. Cardenal, ibid., p. 7.

11. R. Cardenal, ibid., p. 219.

12. Extractos importantes del documento de Mons. Belloso han sido recogidos por Jorge Arias Gómez, en su libro Farabundo Martí, Costa Rica: EDUCA, 1972, pp. 39 58.

13. Texto citado por Arias Gómez, ibíd., p. 45.

14. Ibid., pp. 45-46.

15. Esta tradición fue abolida por Mons. Óscar A. Romero, quien se negó a oficiar cl consabido Te Deum al gobicrno entrante del general Carlos Humberto Romcro, en 1977, como protesta por el ascsinato del P. Rutilio Grande, el 12 de marzo de 1977.

16. El ejemplo más evidentc de esto sucedió en el momento de la elección del nuevo Arzobispo de San Salvador, tras el retiro de Mons. Luis Chávez y González. Entre Mons. Arturo Rivera Damas - un obispo con una orientación demasiado progresista ante los ojos de los grupos de poder- y Mons. Óscar Arnulfo Romero - caractcrizado por sus posicioncs conservadoras-, los grupos de poder presionaron incluso a nivel del Vaticano para la elección del segundo de los candidalos. Como lo atcstigua el mismo Mons. Romero en su Diario, los ofrecimientos económicos se hicicron sentir casi inmediatamente después de su elección, así como cuando el Arzobispo comenzó a dar muestras del viraje religioso y político que lo llevaría a enfrentarse con la oligarquía y el gobierno del general Romero.

17. Para el análisis de esta experiencia del trabajo eclesial en el campo salvadoreño, ver Alvarado López, et al., Conciencia y cambio social en la Hacienda Tres Ceibas (El Salvador). Licenciatura Centroamericana en Sociología, Costa Rica, 1978. 
18. Asistencialismo, porque se trata de llevar a los pobladores del campo una ayuda pastoral que sirviera como paliativo a sus ingentes necesidades. Esta ayuda se canalizaba a través de una instancia eclesial llamada "Cáritas de El Salvador", que a su vez canalizaba —por si hubiese dudas acerca de su carácter asistencial—alimentos, ropa, etc., de Alianza para el progreso.

19. Ver I. Ellacuría, "La Iglesia y las organizaciones populares", en Veinte años..., Vol. II, pp. 659-678.

20. Se trata de la Tercera Carta Pastoral de Mons. Romero y de la primera de Mons. Arturo Rivera Damas. Para un análisis crítico de esta carta pastoral, ver I. Ellacuría, “Comentarios a la carta pastoral", en Veinte años..., Vol. II, pp. 679-732.

21. Ver O. A. Romero y A. Rivera Damas, "La Iglesia y las organizaciones populares", en VVAA, Iglesia de los pobres y organizaciones populares, San Salvador: UCA Editores, 1979.

22. Mons. Romero comienza a abrirse al influjo de Medellín no antes de agosto de 1977, cuando publica su segunda carta pastoral en la que tímidamente aparece citado el documento de Medellín. Ese influjo alcanza su punto más alto cuando el Arzobispo de San Salvador publica su tercera carta pastoral, "La Iglesia y las organizaciones populares", ver J. Delgado, Óscar A. Romero. Biografia, San Salvador: UCA Editores, 1990, pp. 102 y ss.; J. R. Brockman, La palabra queda. Vida de Mons. Óscar A. Romero, San Salvador: CEP-UCA Editores, 1987.

23. R. Cardenal, Historia de una esperanza. Vida de Rutilio Grande, San Salvador: UCA Editores, 1985, p. 143.

24. Los miembros de la jerarquía eclesial que más directamente se confrontaron con la nueva evangelización y directamente con la orientación eclesial de Mons. Romero fueron Pedro Amoldo Aparicio y Quintanilla, Obispo de San Vicente y Secretario General de la CEDES; Benjamín Barrera y Reyes, Obispo de Santa Ana; José Eduardo Alvarez, Obispo de San Miguel y Vicario Castrense; Marco René Revelo, Obispo Auxiliar de San Salvador, y Freddy Delgado, Secretario General de la CEDES.

25. La oposición de la Conferencia Episcopal de El Salvador (a excepción de Mons. Arturo Rivera Damas) a la opción del Arzobispado de San Salvador y del clero cercano a esta opción fue in crescendo desde el desacuerdo con el trabajo pastoral de Rutilo Grande, hasta llegar a la ruptura en los últimos meses del ejercicio de Mons. Óscar Romero. Por su parte, la reacción de la elite del poder comenzó con el estallido de 6 bombas en la Universidad Centroamericana "José Simeón Cañas" y una bomba en la imprenta del Arzobispado, el año 1976, a lo que siguió la expulsión de 6 religiosos extranjeros (2 seminaristas S.J., 1 ex sacerdote S.J., 2 sacerdotes diocesanos y 1 mariknoll), al año siguiente. Este ciclo de violencia contra la Iglesia se continúa con los asesinatos del P. Rutilio Grande y dos campesinos que le acompañaban, así como del P. Alfonso Navarro Oviedo, en 1977; Ernesto Barrerra Moto, en 1978; los padres Octavio Ortiz, Rafael Palacios y Alirio Napoleón Macías, en 1979. Este ciclo de violencia contra la Iglesia alcanza su punto culminante con el asesinato de Mons. Óscar Romero, en marzo de 1980 . Evidentemente, aquí sólo hemos reseñado algunos casos de violencia que afectaron directamente al cuerpo clerical, pero la violencia se hizo sentir con mucha virulencia y con mayor impunidad -durante el período que consideramos y con posterioridad a la muerte de Mons. Romero- sobre religiosas y religiosos, delegados de la palabra y creyentes. Ver Comisión de Dere- 
chos Humanos de El Salvador, La Iglesia en El Salvador, San Salvador: UCA Editores, 1982; J. R. Brockman, La palabra queda..., p. 9 y ss.

26. Pedro Arnoldo Aparicio y Quintanilla, Benjamin Barrera y Reyes, José Eduardo Alvarez, Marco rené Revelo, Freddy Delgado, "Declaración de cuatro Obispos de la Conferencia Episcopal”, 28 de agosto de 1978. En VVAA, Iglesia de los pobres y organizaciones populares, San Salvador: UCA Editores, 1979, pp. 63-65.

27. Comunicado del Consejo Coordinador de FARO, publicado en La Prensa Gráfica el 31 de mayo de 1977. Reproducido en el libro de la Comisión de Derechos Humanos de El Salvador, ya citado, pp. 38-38. Las mayúsculas son del original.

28. Volante citado en el libro de la Comisión de Derechos Humanos de El Salvador, ibid., pp. 40-42. Las mayúsculas son del original.

29. Para un perfil de la figura del P. Rutilio Grande, ver el libro de Rodolfo Cardenal, Historia de una esperanza, ya citado. Para una visión de su pensamiento teológico, ver S. Carranza Oña, Romero-Rutilio. Vidas encontrados, San Salvador: UCA Editores, 1992, pp. 69-143; AAVV, Rutilio Grande. Mártir de la evangelización rural en El Salvador, San Salvador: UCA Editores, 1978.

30. Alocución de Rutilio Grande en la congregación viceprovincial, abril de 1974. Citado por R. Cardenal, Historia de..., p. 205.

31. R. Cardenal, Historia de..., p. 205. El texto de Rutilio Grande citado por Cardenal está tomado de la alocución del primero a la congregación viceprovincial, ya citada.

32. Poema escrito por un poeta popular salvadoreño - anónimo- para conmemorar la fiesta del Divino Salvador del Mundo, patrono de la república. Fragmentos del mismo fueron leídos por Mons. Óscar A. Romero en una de sus homilias masivas en La Catedral de San Salvador. El poema fue musicalizado y se volvió parte de los diversos actos religiosos efectuados en diversas parroquias del país hasta prácticamente 1983, cuando se comienza a operar un viraje hacia prácticas religiosas carismáticas en el conjunto de la Iglesia católica salvadoreña. Esta of ensiva carismática del catolicismo - motivada, en buena medida, por el auge sin precedentes de las sectas protestantes en los años ochenta - se hizo sentir con menos fuerza en las zonas de control del FMLN, o en los campamentos de refugiados situados en Honduras (Mesa Grande y Colomoncagua), donde se mantuvo una lectura comprometida del evangelio. Ver M. López Vigil, Muerte y vida en Morazán. Testimonio de un sacerdote, San Salvador: UCA Editores, 1984.

33. C. R. Cabarrús, ibíd. p. 145. El relato de Cabarrús es tanto más interesante en cuanto que él no sólo investigó como antropólogo la experiencia de Aguilares, sino que se involucró como secerdote jesuita en la tarea evangelizadora encabezada por el padre Grande

34. C. R. Cabarrús, ibid., p. 146.

35. C. R. Cabarrús, ibid., p. 146.

36. C. R. Cabarrús, ibid., p. 148.

37. Ficha de trabajo de C. R. Cabarrús, ibid., p. 170.

38. Ficha de trabajo de C. R. Cabarrús, ibid., p. 149.

39. T. S. Montgomery, "Doce años en El Salvador...”, p. 643.

40. Básicamente, en los departamentos de Morazán, Chalatenango, Usulután, la Libertad y San Miguel. En el departamento de San Salvador, las comunidades eclesiales de base alcanzan un gran auge en el municipio de Aguilares, a $\mathbf{4 0}$ kilómetros de San Salvador, así como las colonias San Ramón, San Antonio Abad y Zacamil. Lamen- 
tablemente, casi no hay documentación disponible sobre el número de comunidades ni sobre la cantidad de sus miembros. La única información sistemática disponible se refiere a la experiencia de Aguilares (Ver el libro de Rodolfo Cardenal, Historia de una esperanzo. Vida de Rutilio Grande), o a la dinámica de una de estas comunidades de la colonia Zacamil, recogida en el libro La fe de un pueblo, San Salvador: UCA Editores, 1984.

41. La experiencia eclesial de Aguilares es la que ha sido mejor estudiada. Ver el libro de Rodolfo Cardenal, Historia de una esperanza. El padre Grande fue el principal pionero de esta nueva forma de inserción eclesial en el campo, inspirada en Medellín. En 1977 fue asesinado por elementos de la Guardia Nacional, en un camino que de Aguilares conduce a San Salvador.

42. T. S. Montgomery, ibid.

43. C. R. Cabarnís, ibid., p. 141.

44. En este punto es pertinente hacer notar que, a nuestro modo de ver, es un error pensar que la organización campesina, gestada en esa época, era una creación puramente eclesial, es decir, que era algo introducido desde fuera, incluso con una planificación previa. La Iglesia sí que animó y respaldó la organización campesina pero, en nuestra opinión, fueron los mismos campesinos quienes decidieron sus formas de organización y la orientación reivindicativa y/o política de las mismas, y esto escapó al control de los grupos eclesiales que quedaron muchas veces a la zaga de la dinámica popular.

45. El proceso de conversión no impacta sólo a los sectores populares campesinos, sino al propio cuerpo eclesial, es decir, a sacerdotes, religiosos y religiosas e incluso al Arzobispo de San Salvador, Mons. Óscar A. Romero. La experiencia de conversión de Mons. Romero supuso el abandono - como señala su biógrafo, el padre Jesús Delgado - de una práctica pastoral sacramentalista, piadosa y espiritual, y la asumpción de una pastoral inspirada en Medellín, que definía como misión fundamental de la Iglesia el acompañamiento a los pobres y a los campesinos de El Salvador. Ver J. Delgado, Óscar A. Romero. Biografia, ya citado.

46. R. Cardenal, Historia de..., p. 270.

47. Las tensiones provienen básicamente de que los miembros de los equipos pastorales tienden a oponerse a una mezcla indistinta entre lo religioso y lo político, mientras que los líderes laicos no perciben en ello un problema e incluso tienden a subordinar lo religioso a lo político. Esto provoca tensiones graves al interior de las comunidades, y entre las misiones religiosas y las diócesis respectivas. La labor pastoral de Rutilio Grande se vio marcada por muchas de estas tensiones. Ver R. Cardenal, Historia de...

48. Nos parece que el ejemplo más notable, a nivel eclesial, de este doble proceso es Mons. Óscar A. Romero, quien efectivamente vivió este proceso de doble conversión religiosa y política. Ver Arzobispado de San Salvador, Monseñor Óscar Arnulfo Romero. Su Diario. Desde el 31 de marzo de 1978 hasta jueves 20 de marzo de 1980. San Salvador, Imprenta Criterio, 1999. El P. Jesús Delgado, en su biografía de Mons. Romero ya citada, hace notar los rasgos más característicos a nivel pastoral de ese proceso de conversión vivido por el Arzobispo mártir de San Salvador.

49. J. Delgado, ibid., p. 143.

50. C. R. Cabarrús, ibid., p. 141.

51. Ficha de trabajo de C. R. Cabarrús, ibid., p. 154. 
52. Ibid.

53. Ver Federación Cristiana de Campesinos Salvadorcños (FECCAS), Carıa de principios, San Salvador, octubre de 1975.

54. C. R. Cabarrús, ibid., p. 163.

55. Ibid.

56. Una muestra del tipo de demandas reivindicativas de FECCAS-UTC sc encucntra en la Pataforma reivindicativa de FECCAS-UTC para la temporada 1978-79 (San Salvador, documento mimeografiado), en la que se plantcan exigencias salariales para la recolección de café, algodón y caña de azúcar.

57. Documento interno de FECCAS, citado por C. R. Cabartús, en ibid.

58. FECCAS-UTC, Boletín internacional, 1, sin fecha de publicación.

59. "FECCAS-UTC a los cristianos de El Salvador y Centroamérica", scptiembre de 1978.

60. Número aproximado de micmbros: $\mathbf{4 0}$ mil. Organizaciones integrantcs: Movimiento Revolucionario Campesino (MRC), Vanguardia Proletaria (VP), Unión Nacional de Jornaleros (UNJ), Asociación Revolucionaria de Estudiantes de Sccundaria (ARDES), Organización Magisterial Revolucionaria (OMR) y Frente Estudiantil Universitario Revolucionario "Salvador Allende" (FUERSA). S. Montes, El Salvador: las fuerzas sociales en la presente coyuntura (enero 1980-diciembre 1983), San Salvador, Departamento de Sociología y Ciencias Políticas de la UCA, 1984, p. 186.

61. FECCAS estuvo ligada inicialmentc a las FAPU, integradas por cl PCS y organizaciones sindicales afines a ćstas, y por cl Frentc Estudiantil Revolucionario Salvador Allende (FUERSA). La ruptura FECCAS-FAPU obedeció básicamente al carácter político que la primera pretendía imprimir a la lucha popular; micntras que las FAPU se centraban en lo meramente reivindicativo. Ver C. R. Cabarrús, ibíd., p. 159 y ss. Posteriormente, las FAPU modifican su posición y se suma a la dinámica gestada por el Bloquc Popular Revolucionario.

62. Número aproximado de miembros: 15 mil. Organizaciones integrantes: Ligas Populares Estudiantiles de Secundaria (LPES), Ligas Populares Obreras (LPO), Ligas Populares Campesinas (LPC) y Ligas Populares Univcrsitarias (LPU).

63. Número aproximado de miembros: 1500 . Organizaciones integrantes: Brigadas Revolucionarias Estudiantiles de Secundaria (BRES), Brigadas de Trabajadores del Campo (BTC), Brigadas Obreras (BO) y Liga para la Libcración (LL). Ver S. Montes, ibid., p. 187.

64. Así como el BPR, los otros frentes de masas (las LP-28, las FAPU y el MLP) contaban entre sus miembros a sectores campesinos que pasaron por un proceso de conversión religioso-político análogo al seguido por los campesinos de FECCASUTC. La escasez de información sobre aquellos impide su análisis; sin embargo, no es un error generalizar la experiencia de Aguilares a otras zonas del agro salvadoreño, como Chalatenango, Morazán o Cabañas, donde grupos importantes de campesinos se organizaron en los diferentes frentes de masas. Asimismo, en éstos hubo sectores no campesinos que llegaron al compromiso revolucionario a través de una conversión religiosa. Para un idea sobre el carácter de estos frentes de masas, lo más acertado es consultar sus documentos programáticos. Ver L.P-28, Proyecto del programa de gobierno democrático-revolucionario de las Ligas Populares 28 de Febrero, San Salvador, 1979; FAPU, Plataforma general del FAPU, San Salvador, 
1979; BPR, FAPU, LP-28, PCS, “EI Salvador: alianzas políticas y proceso revolucionario", Cuadernos de coyuntura, 5, 1979. También sc pucde ver I. Ellacuría, "El papel de las organizaciones populares en la actual situación del país", cn I. Ellacuría, Veinte años..., pp. 733-772.

65. Ver R. Benítez Manaut, La teoría militar y la guerra civil en El Salvador, San Salvador: UCA Editores, 1989, pp. 211-252.

66. Número aproximado de micmbros: 25 mil. Organizaciones intcgrantes: Frentc de Acción Universitaria (FAU), Columna Obrera (CO), Columna Campesina (CC), Columna Magisterial (CM) y Asociación de Estudiantes de Sccundaria (AES). Ver S. Montes, ibíd., p. 186.

67. La incorporación de micmbros de las organizaciones campesinas, especialmente de miembros de FECCAS-UTC, a las cstructuras militares propiamente gucrilleras, sc inicia ya desde la scgunda mitad de los sctenta, pero sc profundiza lucgo de la ofensiva del 10 de encro de 1981, siendo una de sus razones la profundización de la represión gubernamental en el campo. Las bases sociales del FMLN y su fucntc dc aprovisionamiento en las zonas controladas durante el desarrollo de la guerra civil, estarán constituidas justamente por buena parte de csta población campesina. Por otro lado, no hay que perder de vista que estos nuevos cuadros político-militares de procedencia campesina, han radicalizado su compromiso desde una opción cristiana, es decir, en su mayoría son creyentes convencidos, no atcos ni marxista-leninistas.

68. Ver A. Gilly, Guerra y política en El Salvador, México, Nucva Imagen, 1981.

69. Ver K. Lievens, El quinto piso de la alegrla. Tres años con la guerrilla, Ediciones del sistema Radio Venccremos, 1986.

70. Ver R. Benitez Manaut, ibid.

71. F. Ver Cicnfucgos, Veredas de audacia. Historia del FMLN, San Salvador: Arcoiris, 1993.

72. Ver L. A. González, "El Salvador en la postguerra: de la violencia armada a la violencia social", Realidad, 59, pp. 441-458. 